\title{
Erratum to: The Interplay Between NSAIDs and Candida albicans on the Gastrointestinal Tract of Guinea Pigs
}

\author{
George C. Nadăş • Marian A. Taulescu • Lidia Ciobanu • \\ Nicodim I. Fiţ • Chirilă Flore · Sorin Răpuntean • \\ Cosmina M. Bouari $\cdot$ Cornel Catoi
}

Published online: 4 May 2013

(C) Springer Science+Business Media Dordrecht 2013

Erratum to: Mycopathologia (2013) 175:221-230

DOI 10.1007/s11046-013-9613-8

Unfortunately, Figs. 3 and 4 were switched and therefore captioned wrongly. They are given here again in the correct order with correct captions (Figs. 3, 4).

The online version of the original article can be found under doi:10.1007/s11046-013-9613-8.

G. C. Nadăş · N. I. Fiţ · C. Flore · S. Răpuntean Microbiology Department, Faculty of Veterinary Medicine, University of Agriculture Sciences and Veterinary Medicine, 3-5 Calea Mãnãştur Street, 400372 Cluj-Napoca, Romania

M. A. Taulescu $(\bowtie) \cdot$ C. M. Bouari · C. Catoi Pathology Department, Faculty of Veterinary Medicine, University of Agriculture Sciences and Veterinary Medicine, 3-5 Calea Mãnãştur Street, 400372 Cluj-Napoca, Romania e-mail: taulescumarian@yahoo.com

L. Ciobanu

3rd Medical Clinic, Regional Institute of Gastroenterology and Hepatology, University of Medicine and Pharmacy, 19-21 Croitorilor Street, 400162 Cluj-Napoca, Romania 

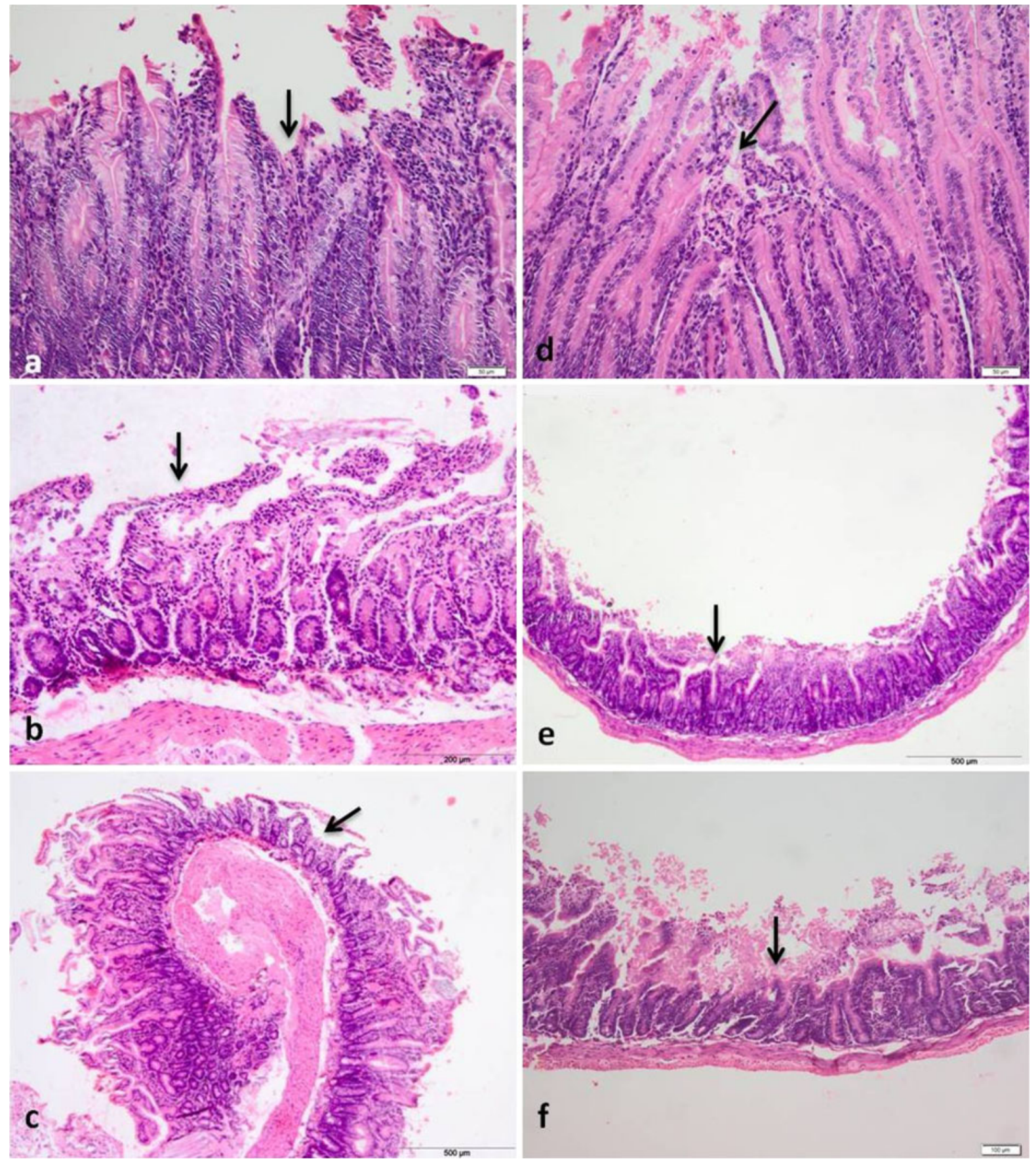

Fig. 3 Histological features of indomethacin-induced small intestine lesions in guinea pigs. a, d Small intestinal mucosa showing a focal and upper villous necrosis (grade 2) and mild to moderate neutrophil infiltration. HE stain, bar $=50 \mu \mathrm{m}$. b, e Small intestinal mucosa revealing diffuse and upper $1 / 3$ villous degeneration (grade 3 ) and extensive neutrophil and

macrophage infiltration in lamina propria. HE stain, bar = $200 \mu \mathrm{m}$, respectively, bar $=500 \mu \mathrm{m}$. c, f Small intestinal mucosa showing multiple and large foci of necrosis of $>1 / 3$ mucosa and moderate to intense neutrophil and macrophage infiltration in lamina propria. HE stain, $b a r=500 \mu \mathrm{m}$, respectively, bar $=100 \mu \mathrm{m}$ 

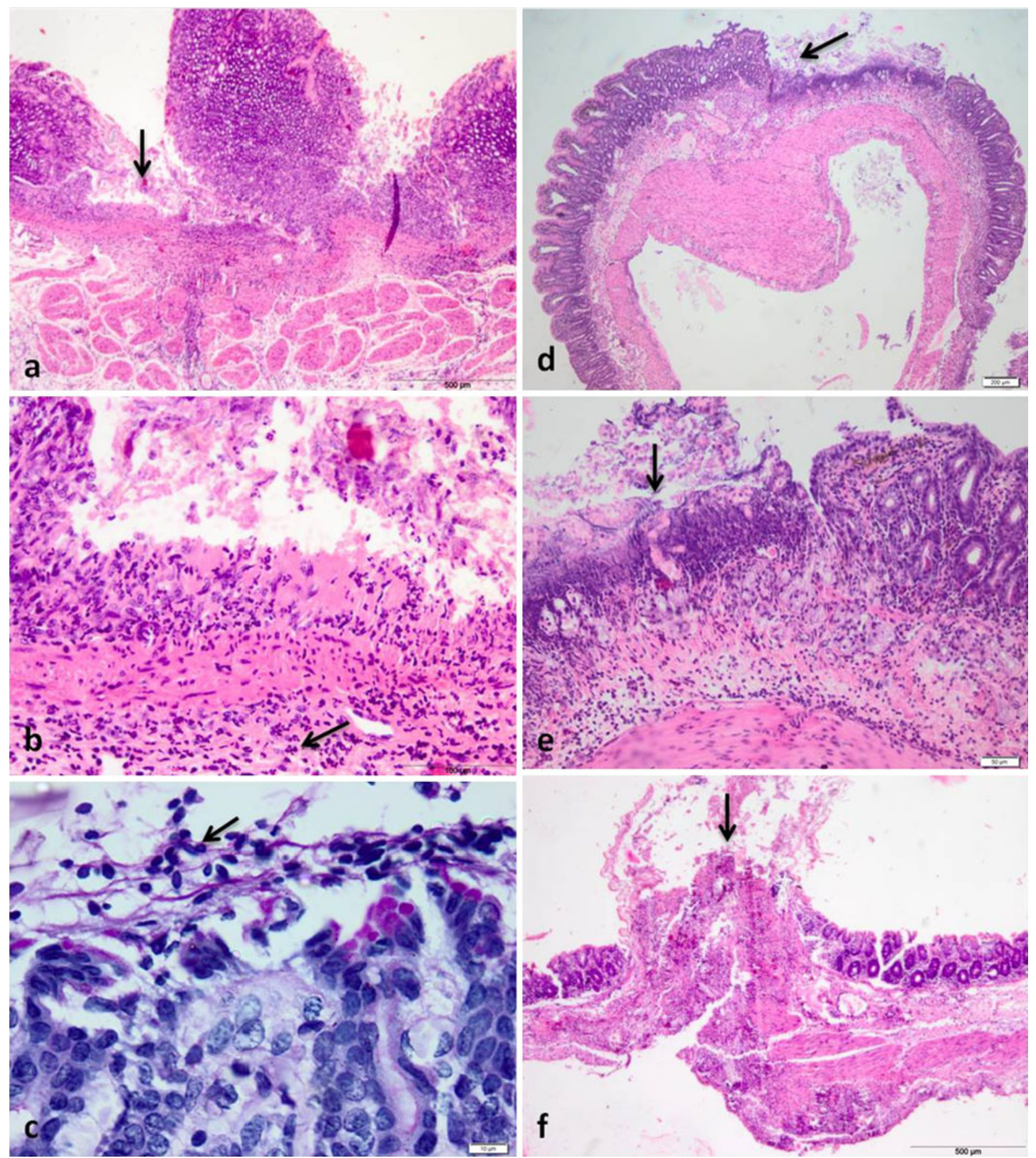

Fig. 4 Microscopical aspects of indomethacin- and Candidainduced small intestine and gastric lesions in guinea pigs. a Stomach showing an acute transmural ulcer (arrow). HE stain, bar $=500 \mu \mathrm{m} ; \mathbf{b}$ extensive neutrophil infiltration in submucosa (arrow). HE stain, bar $=100 \mu \mathrm{m}$; d, e small intestine showing deep necrosis of mucosa and submucosa (arrows) with extensive

neutrophil infiltration and scattered eosinophils in submucosa. HE stain, bar $=200 \mu \mathrm{m}$, respectively, bar $=50 \mu \mathrm{m}$; c surface epithelium of the stomach showing PAS positive Candida cells (arrow), bar $=10 \mu \mathrm{m}$; f large bowel showing an acute perforated ulcer (arrow). HE stain, bar $=500 \mu \mathrm{m}$ 